\title{
Плодоношение шампиньона при укрытии субстрата покровным грунтом
}

\author{
Mushroom fruiting when covering the substrate with a cover soil
}

Девочкина Н.Л., Нурметов Р.Дж., Дугуниева Л.Г.

\section{Аннотация}

В последние годы в нашей стране отмечается положительная динамика роста объемов производства съедобных грибов в Российской Федерации. Объемы производства к 2020 года составили 60 тыс. т (вместо 26 тыс. т в 2018 году). В 2018 году были введены в эксплуатацию крупнейшие грибоводческие комплексы для выращивания шампиньонов в ряде регионов страны: в Калужской, Курской, Ленинградской, Тульской, Пензенской областях, в Республике Татарстан. В мировом рейтинге стран-производителей грибной продукции Россия переместилась с 22 места на 14. Благодаря внедрению новейшей технологии трехфазного приготовления субстрата, интенсификация производственного цикла выращивания плодовых тел шампиньона увеличилась в 1,5 раза. Загрузка субстрата в камеры выращивания теперь происходит одновременно с укрытием его покровным материалом и внесением биодобавки. В статье рассмотрен процесс плодоношения шампиньона при полном цикле производства на примере комплекса в Тульской области. Готовый пророщенный мицелием субстрат механизированным способом перегружается в камеру выращивания с одновременным внесением в него питательной добавки на основе соевого шрота. Питательная добавка с повышенным содержанием белкового азота - хороший активатор для мицелия шампиньона, который получает дополнительный ресурс для мощного ускоренного роста в покровном материале. Слой покровного материала предохраняет верхнюю часть субстрата от испарения, от проникновения воды в субстрат при поливах, исключая отрицательный эффект при контакте мицелия шампиньона с водой. В покровном материале создаются соответствующие условия для активной жизнедеятельности различных групп микроорганизмов, способствующих образованию плодовых тел шампиньона. Материал для приготовления покровной почвы - торф, переходный или низинный. Азотсодержащая добавка позволяет существенно повысить уровень урожайности шампиньона, который по сравнению с контролем (без применения добавки) увеличивается в среднем от 12 до 42\%. При этом уровень рентабельности производства достиг $82 \%$.

Ключевые слова: шампиньон, плодовые тела, плодоношение, технологический процесс, приготовление субстрата, покровный материал, подсев мицелия, биологически активные добавки, система выращивания.

Для цитирования: Девочкина Н.Л., Нурметов Р.Дж., Дугуниева Л.Г. Плодоношение шампиньона при укрытии субстрата покровным грунтом // Картофель и овощи. 2020. №4. С. 22-25. https://doi. org/10.25630/PAV.2020.36.20.008
Devochkina N.L., Nurmetov R.Dzh., Dugunieva L.G.

\section{Abstract}

In recent years in our country there is a positive dynamics of growth of volumes of production of edible mushrooms in the Russian Federation. Production volumes by 2020 amounted to 60 thousand tons (instead of 26 thousand tons in 2018). In 2018, the largest mushroom-growing complexes for growing mushrooms were put into operation in a number of regions of the country: in the Kaluga, Kursk, Leningrad, Tula, Penza regions, and the Republic of Tatarstan. In the world ranking of mushroom producing countries, Russia has moved from 22nd place to 14 . Thanks to the introduction of the latest technology of three-phase preparation of the substrate, the intensification of the production cycle of growing fruit bodies of mushrooms has increased by 1.5 times. Loading the substrate into the growing chambers now occurs simultaneously with covering it with a covering material and adding a bio-additive. The article considers the process of fruiting a mushroom with a full production cycle on the example of a complex in the Tula region. The finished mycelium-sprouted substrate is mechanically reloaded into the growing chamber with simultaneous introduction of a nutritional Supplement based on soy meal. A nutritional Supplement with a high content of protein nitrogen is a good activator for the mycelium of the mushroom, which receives an additional resource for a powerful accelerated growth in the cover material. The layer of cover material protects the upper part of the substrate from evaporation, from water penetration into the substrate during watering, excluding the negative effect when the mycelium of the mushroom comes into contact with water. In the cover material, appropriate conditions are created for the active life of various groups of microorganisms that contribute to the formation of fruit bodies of the mushroom. The material for preparing the cover soil is peat, transitional or low-lying. Nitrogen-containing additives can significantly increase the yield of mushrooms, which in comparison with the control (without the use of additives) increases on average from 12 to $42 \%$. At the same time, the level of profitability of production reached $82 \%$.

Key words: mushroom, fruit bodies, fruiting, technological process, substrate preparation, cover material, mycelium subseeding, biologically active additives, growing system.

For citing: Devochkina N.L., Nurmetov R.Dzh., Dugunieva L.G. Mushroom fruiting when covering the substrate with a cover soil. Potato and vegetables. 2020. No4. Pp. 22-25. https://doi.org/10.25630/ PAV.2020.36.20.008 (In Russ.).
$\mathrm{M}$ ощное энергичное поступательное движение отмечено в промышленном грибоводстве Российской Федерации с 2017 года. Начало этому интенсивному развитию было положено с момента одобрения Экспертным Советом Комитета Совета Федерации по аграрно-продовольственной политике и природопользо- ванию Концепции развития грибоводства на период 2015-2020 годов. При разработке Концепции была заложена и обоснована государственная поддержка предприятий грибного комплекса, оснащения их новейшим инновационным высокопроизводительным технологическим оборудованием. В 2017 году впервые были одобрены льготные кре- диты на инвестиционные проекты по новому строительству грибоводческих предприятий с полным технологическим циклом производства. Результатом этого процесса является положительная динамика роста объемов производства грибной продукции в Российской Федерации. Объемы производства к 2020 года составили 60 тыс. т (вместо 26 тыс. 
т. в 2018 году). В 2018 году были введены в эксплуатацию крупнейшие грибоводческие комплексы для выращивания шампиньонов в ряде регионов страны: в Калужской, Курской, Ленинградской, Тульской, Пензенской областях, в Республике Татарстан. В мировом рейтинге стран-производителей грибной продукции Россия переместилась с 22 места на 14.

Благодаря внедрению новейшей технологии трехфазного приготовления субстрата, интенсификация производственного цикла выращивания плодовых тел шампиньона увеличилась в 1,5 раза. Стало возможным получать рекордные урожаи, более 30 кг грибов с одного квадратного метра полезной площади сооружения, или около 260 кг/м² в год. Принципиально изменился технологический процесс выращивания шампиньона в самом культивационном сооружении, так как загрузка субстрата в камеры выращивания теперь происходит одновременно с укрытием его покровным материалом и одновременным внесением биодобавки, что и определяет особенности последующего плодоношения и интенсивности сбора урожая в больших промышленных камерах выращивания. Интенсивность производственных процессов, выросшая в полтора раза, позволила повысить выход урожая с одного гектара полезной площади до 2,6-2,9 тыс. т свежей грибной продукции.

Многозональная система выращивания грибов сегодня преобладает в мировом и отечественном промышленном грибоводстве. Она определяет структуру производства и состав предприятия, деятельность которого осуществляется по полному технологическому циклу, включающему приготовление субстрата на основе органических материалов, его термическую обработку в специализированных камерах - тоннелях, а также проращивание мицелия гриба в массе субстрата, в тоннелях проращивания. Мы рассмотрим важнейший процесс плодоношения шампиньона при применении полного цикла производства на примере производственного комплекса в Тульской области, где наши специалисты побывали в рамках программы повышения квалификации по грибоводству, которая была подготовлена ВНИИО - филиалом ФГБНУ ФНЦО и Ассоциацией «Теплицы России».

Весь комплекс технологических и организационных мероп- риятий на грибоводческом предприятии направлен на получение высокого товарного урожая плодовых тел шампиньона. Высокий урожай в первую очередь определяется качеством приготовленного субстрата. Особенностью новой технологии трехфазного приготовления субстрата является то, что принятая современная система, так называемая «трехзональная» благодаря техническим решениям, разработке и внедрению системы машин (рис. 1), позволила разделить в пространстве и во времени основные технологические процессы. А именно, предварительной подготовки исходных компонентов субстрата и проведение контролируемой ферментации в бункерах с аэрируемыми полами, термической обработки субстрата в тоннелях и проращивания мицелия гриба также в больших массах субстрата в тоннелях, аналогичных камерам термообработки. Важны преимущества инновационной технологии приготовления субстрата, которые заключаются в экономичности использования исходных материалов, снижении энергоемкости производства на единицу продукции, высокой производительности труда, так как в технологическом процессе приготовления субстрата минимизированы затраты ручного труда за счет $100 \%$-ной механизации и автоматизации трудоемких процессов. Кроме того, эта технология высокоточная, так как полноценно обеспечивает условия микроклимата, контролирует их и управляет ими в заданном режиме. На выходе продукт имеет четкие технологические показатели, обеспечивающие высокую продуктивность субстрата [1].

В культивационную камеру на плодоношение субстрат попадает полностью зарощенным мицелием гриба, что обеспечивает ему высокую конкурентно способность по сравнению с другими микроорганизмами, являющимися патогенами для шампиньона.

Цель: оценить эффективность технологии выращивания шампиньона при использовании покровного материала.

Условия, материалы и методы исследований

Для определения эффективности новых применяемых технологических операций использована методика сравнительного технологического анализа по основным параметрам технологии культивирования шампиньона в зависимости от применяемой системы выращивания. Экспериментальная работа проведена на базе производственного шампиньонного комплекса ООО «Агрогриб» (Тульская область) в 2018-2019 годах на технологическом оборудовании фирмы «Христианс групп» (Нидерланды)

\section{Результаты исследований}

Новая технологическая система предполагает выгрузку субстрата из тоннеля проращивания, т.е. после третьей фазы. Фактически это новый продукт, который получают на предприятиях по централизованному приготовлению шампиньонных субстратов [2]. В нашем случае, цех приго-

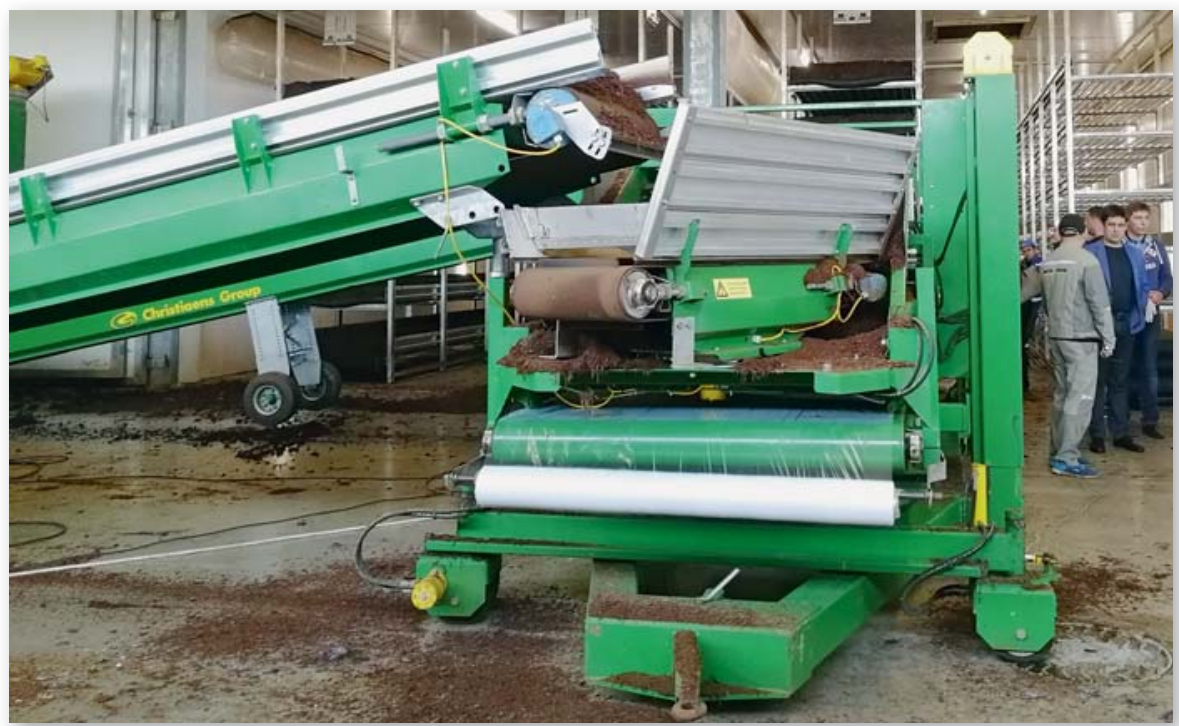

Рис. 1. Система транспортеров для одновременной загрузки субстрата фазы 3 и покровного материала 
Основные технологические и производственные показатели в зависимости от системы выращивания шампиньона (2018-2019 годы)

\begin{tabular}{|c|c|c|}
\hline \multirow{2}{*}{ Показатель } & \multicolumn{2}{|c|}{ Система выращивания } \\
\hline & Двухзональная & Трехзональная \\
\hline $\begin{array}{l}\text { Удельный расход субстрата на } 1 \text { м² (после термо- } \\
\text { обработки), кг }\end{array}$ & 75 & 90 \\
\hline Планируемая урожайность, кг/м² & 25 & 30 \\
\hline Годовой выход продукции, кг/м² & 140 & 258 \\
\hline $\begin{array}{l}\text { Расчетная себестоимость } 1 \text { кг грибов, р/кг } \\
\text { (в ценах } 2019 \text { года) }\end{array}$ & 90 & 77 \\
\hline $\begin{array}{l}\text { Уровень рентабельности производства,\% } \\
\text { (при среднегодовой цене реализации } 140 \text { р/кг) }\end{array}$ & 55 & 82 \\
\hline
\end{tabular}

товления субстрата является подразделением шампиньонного комплекса. Готовый пророщенный мицелием субстрат механизированным способом перегружается в камеру выращивания с одновременным внесением в него питательной добавки на основе соевого шрота. Питательная добавка с повышенным содержанием белкового азота - хороший активатор для мицелия шампиньона, который получает дополнительный ресурс для мощного ускоренного роста в покровном материале. Покровный материал - среда, в которой происходит главный процесс - плодоношение шампиньона.

Покровный материал, как неотъемлемая часть среды обитания шампиньона, выполняет определенные функции, связанные с его свойствами: влагоемкостью, воздухопроницаемостью, уровнем содержания питательных веществ. Слой покровного материала предохраняет верхнюю часть субстрата от испарения, от проникновения воды в субстрат при поливах, исключая отрицательный эффект при контакте мицелия шампиньона с водой. Тем самым осуществляется регулирование теплового, газового и водного обмена между субстратом и окружающей средой помещения. Кроме того, в покровном материале создаются соответствующие условия для активной жизнедеятельности различных групп микроорганизмов, способствующих образованию плодовых тел шампиньона. Основным исходным материалом для приготовления покровной почвы является торф, переходный или низинный, который отвечает всем требованиям, перечисленным ранее.

Внесение питательных добавок с целью повышения урожайности и улучшения качества плодовых тел шампиньона сегодня широко применяют в современной технологии культивирования съедобных грибов [3]. Наиболее распространенная добавка - мука соевых или хлопковых семян. Многочисленными исследованиями и грибоводческой практикой были установлены дозы, время, порядок (способ) внесения питательных добавок. Так, на основании исследований A. Overstijns (1981) установил значительное увеличение выхода плодовых тел шампиньона при внесении 1 кг муки хлопковых семян к 100 кг субстрата с проросшим мицелием в момент укрытия субстрата покровным материалом [4].

При проведении лабораторных экспериментов исследователь получил повышение урожая грибов - 4,5-

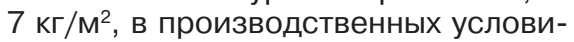
ях при внесении 1\% соевой муки в среднем 3 кг/м². При этом было отмечено, что белковую добавку из соевой муки перед внесением в субстрат необходимо подвергнуть термической обработке, а соевую муку целесообразно равномерно распределять по поверхности субстрата и перемешать с ним.

Внесение белковых добавок провоцирует активацию роста мицелия шампиньона в первые 4-5 дней после укрытия покровным грунтом. В эти же дни происходит всплеск температуры в субстрате, поэтому в данный период рекомендуется строго следить за его температурой, обеспечивая температурный уровень в оптимальных пределах $24-26^{\circ} \mathrm{C}$, и при необходимости (при повышении температуры более $28^{\circ} \mathrm{C}$ ) вентилировать камеру выращивания свежим воздухом. Азотсодержащая добавка позволяет существенно повысить уровень урожайности шампиньона, который по сравнению с контролем (без применения добавки) увеличивается в среднем от 12 до 42\%.

В среднем по факту этот уровень в производственных условиях составил 3-5 кг дополнительного урожая с одного квадратного метра полезной площади камеры выращивания шампиньонницы [5].

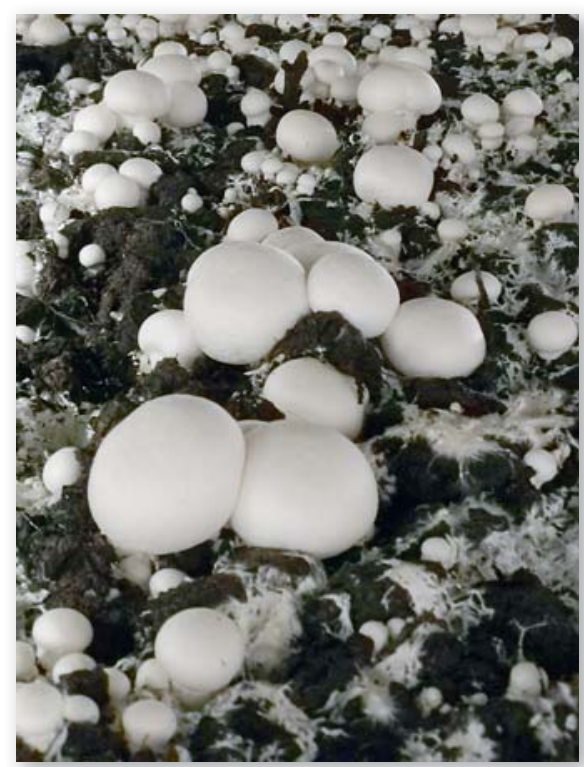

Рис. 2. Плодоношение шампиньона белой расы

Общая продолжительность вегетативной фазы роста мицелия шампиньона через покровный материал составляет в среднем 14 суток и 18 суток до начала плодоношения шампиньона и первого сбора урожая (рис. 2.).

Интенсификация технологических процессов за счет оптимизации условий их проведения и ускорения продолжительности отдельных фаз на 10-12\% определяет технологические и экономические показатели новой системы производства (табл.).

В связи с выделением зоны проращивания мицелия в массе субстрата изменилось количество оборотов культуры в год. Двухзональная система производства, которая применялась ранее, обеспечивала 5,6 оборотов. Трехзональная система перешла на 8,6 оборотов в год. За счет увеличения расхода субстрата на квадратный метр полезной площади и применения биологически активной добавки повысилась урожайность шампиньона более чем на $12 \%$. При этом уровень рентабельности производства достиг $82 \%$, т.е. в 1,5 раза больше, чем при двухзональной системе.

\section{Выводы}

Новейшая инновационная технология выращивания шампиньона с использованием современных технологических и технических решений требует пристального технологического внимания к проведению операций по приготовлению субстрата и укрытию его покровным материалом, с учетом особенностей одно- 
временного внесения биологически активных добавок в субстрат.

Применение новых операций в производственном процессе изме- няет нормативы технологии (удельный расход субстрата 85 кг/м²) и позволяет существенно интенсифицировать процесс производства, до- стигая максимальных показателей по урожайности шампиньона (30 и более кг $\left./ \mathrm{M}^{2}\right)$ и экономической эффективности (более 80\%).

\section{Библиографический список}

1.Девочкина Н.Л., Нурметов Р.Дж., Алексеева К.Л. Инновационная технология трехфазного приготовления субстрата для культивирования шампиньона // Теплицы России. 2016. №3. С. 55-60.

2.Девочкина Н.Л., Селиванов В.Г. Инновационные технологии и технические средства для производства грибов в защищенном грунте. М.: ФГБНУ «Росинформагротех». 2014. 135 С.

3.Алексеева К.Л. Научные основы культивирования и защиты съедобных грибов от вредителей и болезней: автореф. дисс. ... доктора с.-х. наук. М., 2002. 46 с.

4.Overstijns A. Supplementing mushroom compost after peakheating. Mushroom J.1981. No106. Pp. 350-352.

5.Скоблицов А.Ю. Технологический процесс выращивания шампиньонов на компосте фазы 3 // Теплицы России. 2019. №4. C. 88-89.

\section{References}

1.Devochkina N.L., Nurmetov R.Dzh., Alekseeva K.L. Innovative technology of three-phase substrate preparation for mushrooms cultivation. Greenhouses of Russia. 2016. No3. Pp. 55-60 (In Russ.). 2.Devochkina N.L., Selivanov V.G. Innovative technologies and technical means for the production of mushrooms in protected ground. Moscow. FSBSI Rosinformagrotech. 2014. 135 p. (In Russ.).

3.Alekseeva K.L. Scientific bases of edible mushrooms cultivation and protection from pests and diseases: abstract of thesis of Doctor Sci. (Agr.). Moscow. 2002. 46 p. (In Russ.).

4.Overstijns A. Supplementing mushroom compost after peakheating. Mushroom J.1981. No106. Pp. 350-352.

5.Skoblitsov A.Yu. Technological process of growing mushrooms on compost of III phase. Greenhouses of Russia. 2019. No4. Pp. 8889 (In Russ.).

\section{Об авторах}

Девочкина Наталия Леонидовна, доктор с.-х. наук, г.н.с. отдела защищенного грунта и грибоводства, ВНИИО-филиал ФГБНУ ФНЦО. E-mail: green-hothouse@mail.ru

Нурметов Рафик Джамович, доктор с.-х. наук, профессор, г.н.с. отдела защищенного грунта и грибоводства, ВНИИОфилиал ФГБНУ ФНЦО. E-mail: vniioh@yandex.ru

Дугуниева Лариса Гамидовна, м.н.с. отдела защищенного грунта и грибоводства, ВНИИО-филиал ФГБНУ ФНЦО. E-mail: vniioh@yandex.ru

\section{Authors details}

Devochkina N.L. Doctor Sci. (Agr.)., chief research fellow, department of greenhouse industry and mushroom cultivation, ARRIVG - branch of FSBSI FSVC. E-mail: green-hothouse@mail.ru

Nurmetov R.D., Doctor Sci. (Agr.), professor, chief research fellow, department of greenhouse industry and mushroom cultivation, ARRIVG - branch of FSBSI FSVC. E-mail: vniioh@yandex.ru

Dugunieva L.G., junior research fellow, department of greenhouse industry and mushroom cultivation, ARRIVG - branch of FSBSI FSVC. E-mail: vniioh@yandex.ru

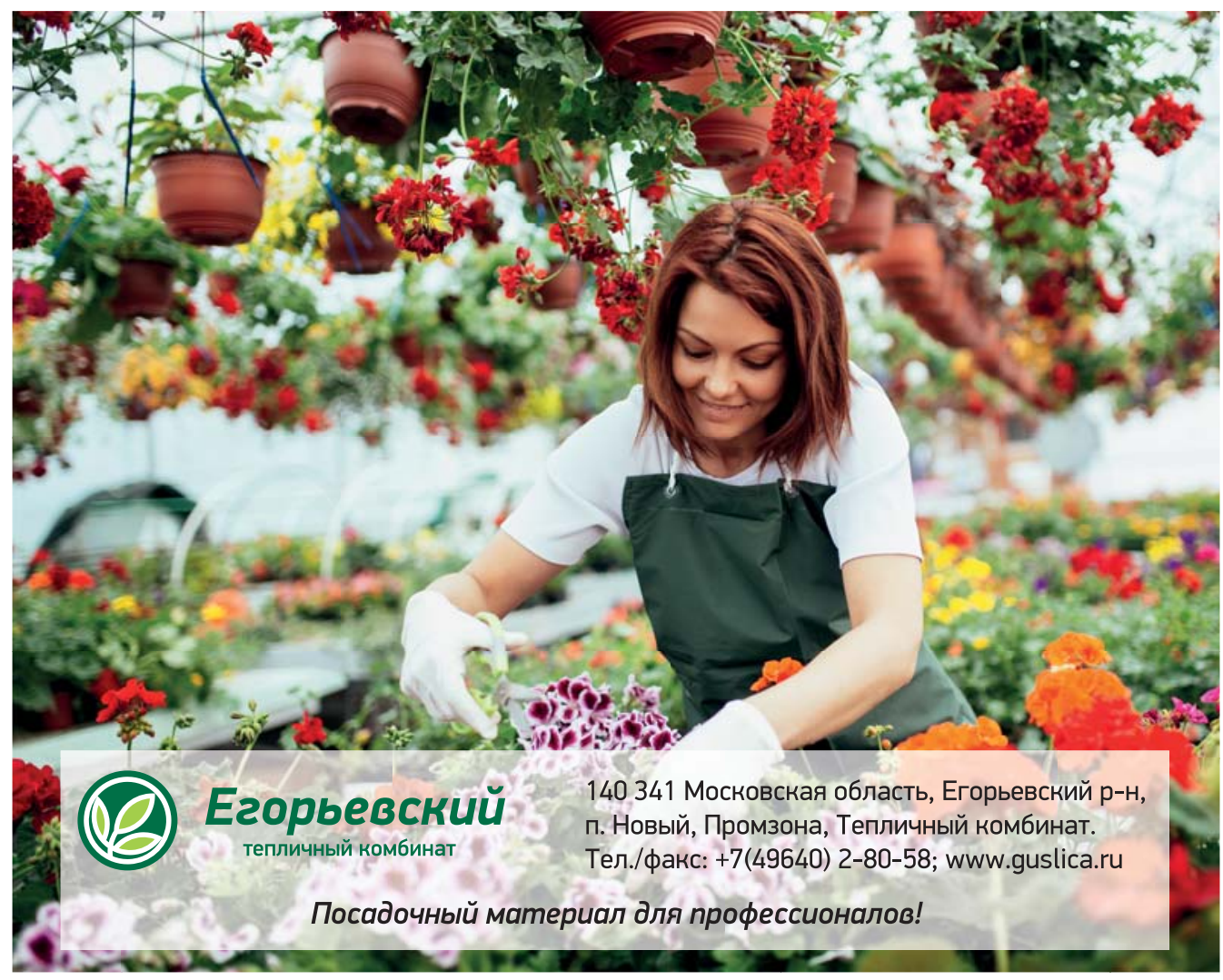

